Table 1. Baseline characteristics and third interim analysis data of patients with FMF

\begin{tabular}{|c|c|c|c|c|c|c|c|c|}
\hline \multirow[b]{3}{*}{ Number of patients, $\mathrm{N}$} & \multicolumn{2}{|c|}{ Baseline } & \multicolumn{2}{|c|}{6 months } & \multicolumn{2}{|c|}{12 months } & \multicolumn{2}{|c|}{18 months } \\
\hline & \multicolumn{8}{|c|}{ All patients | patients without prior CAN therapy } \\
\hline & 54 & 11 & 35 & 7 & 27 & 5 & 16 & 3 \\
\hline $\begin{array}{l}\text { Number }\left(\%^{*}\right) \text { of patients in disease remis- } \\
\text { sion (physician assessment) }\end{array}$ & $18(48.6)$ & $1(20.0)$ & $19(73.1)$ & $3(75.0)$ & $13(65.0)$ & $1(50.0)$ & $8(61.5)$ & $1(100.0)$ \\
\hline $\begin{array}{l}\text { Physician Global Assessment, percentage* } \\
\text { of absent/mild-moderate/severe rating }\end{array}$ & $43 / 38 / 11$ & $0 / 40 / 60$ & $65 / 27 / 0$ & $50 / 50 / 0$ & $55 / 35 / 0$ & $0 / 50 / 0$ & $46 / 46 / 0$ & 0/100/0 \\
\hline $\begin{array}{l}\text { Patient assessment of current disease } \\
\text { activity; } 0-10, \text { median (min; } \max )\end{array}$ & $3.0(0 ; 10)$ & $7.0(0 ; 10)$ & $2.5(0 ; 7)$ & $2.0(0 ; 5)$ & $2.0(0 ; 7)$ & $2.0(0 ; 2)$ & $2.0(0 ; 6)$ & $0.5(0 ; 1)$ \\
\hline $\begin{array}{l}\text { Patient assessment of current fatigue; } 0-10 \text {, } \\
\text { median (min; max) }\end{array}$ & $5.0(0 ; 10)$ & $5.0(0 ; 9)$ & $3.5(0 ; 10)$ & $3.0(1 ; 6)$ & $3.0(0 ; 10)$ & $0.0(0 ; 4)$ & $3.0(0 ; 7)$ & $0.5(0 ; 1)$ \\
\hline $\begin{array}{l}\text { Number }\left(\%^{*}\right) \text { of patients without impairment } \\
\text { of social life by the disease }\end{array}$ & $19(46.3)$ & $3(37.5)$ & $18(66.7)$ & $3(75.0)$ & $14(66.7)$ & $4(80.0)$ & $5(55.6)$ & $2(66.7)$ \\
\hline CRP, median (mg/dl) & 0.2 & 1.1 & 0.2 & 0.1 & 0.2 & 0.0 & 0.1 & 0.5 \\
\hline SAA, median (mg/dl) & 0.7 & 6.8 & 0.8 & 0.4 & 0.8 & 0.6 & 0.6 & 0.7 \\
\hline ESR, median (mm/h) & 9.0 & 18.5 & 6.0 & 5.0 & 5.5 & 4.0 & 8.0 & 5.0 \\
\hline \multicolumn{5}{|c|}{ Number of events } & \multicolumn{4}{|c|}{ Incidence rate per 100 patient years } \\
\hline Total & \multicolumn{4}{|c|}{11} & \multicolumn{4}{|c|}{16.23} \\
\hline Arthritis & \multicolumn{4}{|c|}{5} & \multicolumn{4}{|c|}{7.38} \\
\hline SARS-CoV-2 infection & \multicolumn{4}{|c|}{2} & \multicolumn{4}{|c|}{2.95} \\
\hline Familial Mediterranean Fever & \multicolumn{4}{|c|}{1} & \multicolumn{4}{|c|}{1.48} \\
\hline Intestinal Hemorrhage & \multicolumn{4}{|c|}{1} & \multicolumn{4}{|c|}{1.48} \\
\hline Pyrexia & \multicolumn{4}{|c|}{1} & \multicolumn{4}{|c|}{1.48} \\
\hline Tonsillectomy (SADR) & \multicolumn{4}{|c|}{1} & \multicolumn{4}{|c|}{1.48} \\
\hline
\end{tabular}

${ }^{*}$ not reported for all patients

CRP, c-reactive protein; ESR, erythrocyte sedimentation rate; n. a., not annotated; SAA, serum amyloid A; SADR, serious adverse drug reaction; SAE, serious adverse event

disease activity, fatigue and impact on social life by patients' assessment, inflammatory markers and AIDAI (Auto-Inflammatory Diseases Activity Index) score were recorded at baseline and were assessed at 6-monthly intervals within the three-year observation period of the study.

Results: This interim analysis of FMF patients $(\mathrm{N}=54)$ enrolled by December 2020 includes baseline as well as 6-, 12- and 18-month data. Mean age in this cohort was 25 years (4-56 years) and the proportion of female patients was 46 $\%(\mathrm{~N}=25)$. At baseline, median duration of prior CAN treatment was 2.0 years (0-6 years).

While physician ratings report around $62 \%$ of patients in disease remission, $52 \%$ with absent and $34 \%$ with mild-moderate disease activity, patient-reported disease activity decreased from moderate (PPA 3.0) to low (PPA 2.0) during the observation period. A decrease was observed regarding disease activity parameters, in particular in patients without prior CAN therapy (Table 1, Figure 1). A total of 11 serious adverse events was reported, of which one case of tonsillectomy was classified as drug-related.

Conclusion: Interim data of FMF patients from the RELIANCE study, the longest running real-life CAN registry, confirm efficacy and safety of long-term CAN treatment.

REFERENCES:

[1] Ozen S, et al. EULAR recommendations for the management of familial Mediterranean fever. Ann Rheum Dis 2016;75:644-651. doi:10.1136/ annrheumdis-2015-208690

[2] De Benedetti $F$, et al. Canakinumab for the treatment of autoinflammatory recurrent fever syndromes. N Engl J Med 2018;378:1908-19.

Figure 1: Median AIDAl score (0-390) of the FMF main group ( $N=54$, at baseline) and the FMF subgroup without prior CAN therapy ( $N=11)$ within 18 months



Disclosure of Interests: Jörg Henes Consultant of: Novartis, AbbVie, Sobi, Roche, Janssen, Boehringer-Ingelheim, Grant/research support from: Novartis, Roche, J. B. Kuemmerle-Deschner Consultant of: Novartis, AbbVie, Sobi, Grant/ research support from: Novartis, AbbVie, Sobi, Tilmann Kallinich Consultant of: Sobi, Novartis, Roche, Grant/research support from: Novartis, Frank Dressler Consultant of: Abbvie, Mylan, Novartis, Pfizer, Grant/research support from: Novartis, Frank Weller-Heinemann: None declared, Birgit Kortus-Goetze Consultant of: Novartis, Ivan Foeldvari Consultant of: Novartis, Gerd Horneff Speakers bureau: bbVie, Bayer, Chugai, Merck Sharp \& Dohme, Novartis, Pfizer, Roche Grant/research support from: AbbVie, Chugai, Merck Sharp \& Dohme, Novartis Pfizer, Roche, Markus Hufnagel Grant/research support from: Novartis, Florian Meier Speakers bureau: Novartis, Julia Weber-Arden Employee of: Novartis, Nor bert Blank Consultant of: Novartis, Sobi, Lilly, Pfizer, Abbvie, BMS, MSD, Actelion, UCB, Boehringer-Ingelheim, Roche, Grant/research support from: Novartis, Sobi DOI: 10.1136/annrheumdis-2021-eular.3756

\section{POS1380 LONG-TERM EFFICACY AND SAFETY OF CANAKINUMAB IN PATIENTS WITH TRAPS (TUMOR NECROSIS FACTOR RECEPTOR-ASSOCIATED PERIODIC SYNDROME) - INTERIM ANALYSIS OF THE RELIANCE REGISTRY}

N. Blank ${ }^{1}$, J. Henes ${ }^{2}$, T. Kallinich ${ }^{3}$, P. Oommen ${ }^{4}$, C. Schuetz ${ }^{5}$, M. Borte ${ }^{6}$, J. Weber-Arden ${ }^{7}$, J. B. Kuemmerle-Deschner ${ }^{8} .{ }^{1}$ University Hospital Heidelberg, Rheumatology, Heidelberg, Germany; ${ }^{2}$ University Hospital Tuebingen, Department of Internal Medicine II, Rheumatology, Tuebingen, Germany; ${ }^{3}$ Charité University Medicine Berlin, Department of Pediatrics, Division of Pulmonology, Immunology and Critical Care Medicine, Berlin, Germany; ${ }^{4}$ Heinrich-Heine-University Düsseldorf, Clinic of Pediatric Hematology, Oncology and Clinical Immunology, Duesseldorf, Germany; ${ }^{5}$ Medizinische Fakultät Carl Gustav Carus, Technische Universität Dresden, Pediatrics, Dresden, Germany; ${ }^{6}$ Hospital St. Georg g GmbH Leipzig, ImmunoDeficiencyCenter Leipzig (IDCL), Leipzig, Germany; ${ }^{7}$ Novartis Pharma $\mathrm{GmbH}$, Novartis Pharma GmbH, Nuernberg, Germany; ${ }^{8}$ University Hospital Tuebingen, Department of Pediatrics, Division of Pediatric Rheumatology, Tuebingen, Germany

Background: Tumor necrosis factor receptor-associated periodic syndrome (TRAPS) is a rare autoinflammatory condition characterized by severe systemic and organ inflammation. In a phase 3 pivotal trial (CLUSTER study), TRAPS patients have been successfully treated with the interleukin-1 $\beta$ inhibitor canakinumab. $45 \%$ of patients reached clinical remission after 16 weeks (primary endpoint $)^{1}$. Canakinumab has been approved and applied for the treatment of TRAPS patients since $2017^{2}$.

Objectives: The present study explores the long-term efficacy and safety of canakinumab under routine clinical practice conditions in pediatric (age $\geq 2$ years) and adult TRAPS patients. 
Table 1. Baseline characteristics and interim analysis data of patients with TRAPS

\begin{tabular}{|c|c|c|c|c|}
\hline & Baseline & 6 months & 12 months & 18 months \\
\hline Number of patients, $\mathrm{N}$ & 16 & 13 & 10 & 6 \\
\hline Median age, years (min; max) & $23(3 ; 43)$ & $17(3 ; 43)$ & $16(4 ; 38)$ & $25(4 ; 43)$ \\
\hline Females (\%) & $11(69)$ & $9(69)$ & $7(70)$ & $3(50)$ \\
\hline Median duration of prior CAN therapy at baseline, years ( $\min ; \max$ ) & $1.0(0 ; 4)$ & $1.0(0 ; 4)$ & $1.0(0 ; 4)$ & $1.5(0 ; 2)$ \\
\hline Number (\%) of patients in disease remission (physician assessment) & $9(60.0)$ & $9(81.8)$ & $7(77.8)$ & $4(80.0)$ \\
\hline Physician Global Assessment, percentage of absent/mild-moderate/severe rating & $40 / 53 / 0$ & $82 / 9 / 0$ & $44 / 44 / 11$ & $80 / 20 / 0$ \\
\hline Patient assessment of current disease activity; $0-10$, median ( $\min ; \max$ ) & $1.5(0 ; 5)$ & $1.0(0 ; 4)$ & $1.0(0 ; 6)$ & $0.0(0 ; 3)$ \\
\hline Patient assessment of current fatigue; $0-10$, median ( $\min ; \max$ ) & $2.0(0 ; 8)$ & $1.0(0 ; 7)$ & $2,5(0 ; 8)$ & $4.0(0 ; 7)$ \\
\hline Number (\%) of patients without impairment of social life by the disease & $4(50)$ & $5(63)$ & $2(33)$ & $3(60)$ \\
\hline Number $(\%)$ of patients with days absent from work/school during last 6 months & $8(50)$ & $5(39)$ & $5(56)$ & $3(50)$ \\
\hline CRP, median (mg/dl) & 0.1 & 0.1 & 0.1 & 0.0 \\
\hline SAA, median (mg/dl) & 0.5 & 0.4 & 0.4 & 0.3 \\
\hline ESR, median $(\mathrm{mm} / \mathrm{h})$ & 7.0 & 5.0 & 5.0 & 5.0 \\
\hline SAE & \multicolumn{2}{|c|}{ Number of events } & \multicolumn{2}{|c|}{ Incidence rate per 100 patient years } \\
\hline Total & \multicolumn{2}{|c|}{3} & \multicolumn{2}{|c|}{14.7} \\
\hline Circulatory collapse (non fatal) & \multicolumn{2}{|c|}{1} & \multicolumn{2}{|c|}{4.9} \\
\hline Dizziness & \multicolumn{2}{|c|}{1} & \multicolumn{2}{|c|}{4.9} \\
\hline Headache & \multicolumn{2}{|c|}{1} & \multicolumn{2}{|c|}{4.9} \\
\hline
\end{tabular}

CRP, c-reactive protein; ESR, erythrocyte sedimentation rate; SAA, serum amyloid A; SAE, serious adverse event

Methods: RELIANCE is a prospective, non-interventional, multi-center, observational study based in Germany with a 3-year follow-up period. Patients with clinically confirmed diagnoses of TRAPS, CAPS, FMF or HIDS/MKD who routinely receive canakinumab are enrolled in order to evaluate efficacy and safety of canakinumab under standard clinical practice conditions. Disease activity and remission by physician assessment, disease activity and fatigue by patient assessment, days absent from school/work due to study indication, inflammatory markers, and AIDAI (Auto-Inflammatory Diseases Activity Index) score were assessed at baseline and at 6-monthly intervals.

Results: The interim analysis of TRAPS patients enrolled by December 2020 includes baseline ( $\mathrm{N}=16$, including 1 patient with atypical TRAPS) and preliminary 18-month data. Mean age in this cohort was 23 years (3-43 years) and the median duration of prior CAN treatment was 1.0 year ( $0-4$ years).

Physician assessment indicated $60-80 \%$ remission and laboratory parameters were within normal range. Disease control by patient assessment showed no major changes regarding the analyzed parameters (Table 1, Figure 1). Of the three serious adverse events reported none was classified as drug-related.

Conclusion: Preliminary analysis of 18 month interim data of TRAPS patients treated with CAN available from the RELIANCE study indicate stable efficacy and safety of CAN long-term treatment.

\section{REFERENCES}

[1] De Benedetti $F$, et al. Canakinumab for the treatment of autoinflammatory recurrent fever syndromes. N Engl J Med 2018;378:1908-19.

[2] Ilaris, INN-canakinumab (europa.eu)
Figure 1: Median AIDAI score (0-390) of the TRAPS patients ( $N=16$ at baseline) within 18 months

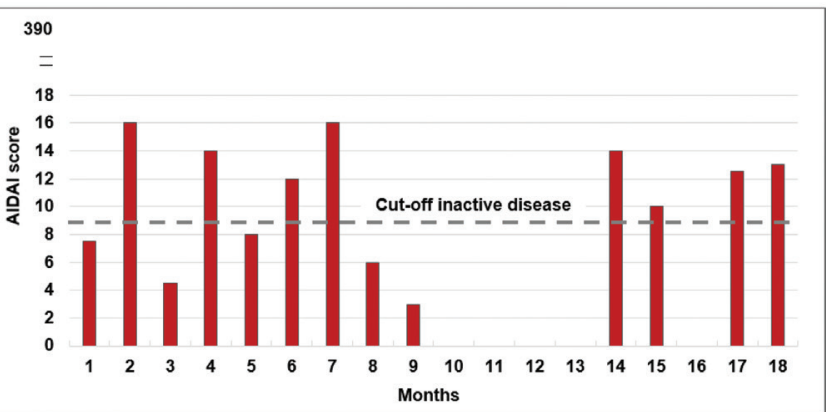

Disclosure of Interests: Norbert Blank Consultant of: Novartis, Sobi, Lilly, Pfizer, Abbvie, BMS, MSD, Actelion, UCB, Boehringer-Ingelheim, Roche, Grant/research support from: Novartis, Sobi, Jörg Henes Consultant of: Novartis, AbbVie, Sobi, Roche, Janssen, Boehringer-Ingelheim, Grant/research support from: Novartis, Roche, Tilmann Kallinich Consultant of: Sobi, Novartis, Roche, Grant/research support from: Novartis, Prasad Oommen Grant/research support from: Novartis, Catharina Schuetz: None declared, Michael Borte Grant/research support from: Pfizer Shire, Julia Weber-Arden Employee of: Novartis, J. B. Kuemmerle-Deschner Consultant of: Novartis, AbbVie, Sobi, Grant/research support from: Novartis, AbbVie, Sobi DOI: 10.1136/annrheumdis-2021-eular.3808 